\title{
Clinical Characteristics and Difficulties in the Management of Cancer of the Penis
}

\section{Kimassoum Rimtebaye ${ }^{1 *}$, Mahamat Ali Mahamat ${ }^{1}$, Freddy Rimtebaye Kimassoum ${ }^{1}$, Frederic Meurde Nemia ${ }^{2}$, Antoinette Djekoundade ${ }^{3}$, Valentin Andjeffa ${ }^{4}$, Valentin Vadandi5, Koldjimadje Mingue ${ }^{1}$}

${ }^{1}$ Urology Department, University Hospital of National Reference, N’Djamena, Chad

${ }^{2}$ Anatomopathology Department, University Hospital of National Reference, N’Djamena, Chad

${ }^{3}$ Dermatology Department, University Hospital of National Reference, N’Djamena, Chad

${ }^{4}$ Traumatology-Orthopedics Department, University Hospital of National Reference, N'Djamena, Chad

${ }^{5}$ University Hospital Center, Abéché, Chad

Email: ^rimtebayek@gmail.com

How to cite this paper: Rimtebaye, K., Ali Mahamat, M., Rimtebaye Kimassoum, F., Meurde Nemia, F., Djekoundade, A., Andjefa, V., Vadandi, V. and Mingue, K. (2021) Clinical Characteristics and Difficulties in the Management of Cancer of the Penis. Open Journal of Urology, 11, 436-442. https://doi.org/10.4236/oju.2021.1111043

Received: July 3, 2021

Accepted: November 27, 2021

Published: November 30, 2021

Copyright $\odot 2021$ by author(s) and Scientific Research Publishing Inc. This work is licensed under the Creative Commons Attribution International License (CC BY 4.0).

http://creativecommons.org/licenses/by/4.0/

\begin{abstract}
Introduction: Penile cancer is a rare primary malignancy that occurs in patients in their 60 s and 70s. The aim of the study was to describe the anatomical aspects of penile cancer and to report the difficulties of its management. Materials and Methods: This was a retrospective descriptive study of patients with penile tumors from January 2007 to December 2019. Patients of sexual age with an ulcerated lesion of the penis, who came to our department and whose clinical and paraclinical workup led to the diagnosis of penile cancer, were included. The variables studied were clinical, paraclinical and therapeutic. Results: In 12 years, we diagnosed and managed 8 patients with penile cancer, an incidence of 0.7 per year. The reason for consultation was the chronic ulcerating wound of the penis with a "cauliflower" aspect. The first medical consultation was late $(n=8)$ after a long latency period lost to traditional healers. The lesion was located in the glans penis $(n=6)$ and/or in the corpus cavernosum $(n=2)$. Histological analysis of the cores concluded to a squamous cell carcinoma. Patients were classified as $\mathrm{T} 2 \mathrm{~N}+\mathrm{M}+(\mathrm{n}=3)$ and T2N0M0 $(n=5)$. One patient had accepted partial amputation of the penis. Conclusion: Penile cancer is a rare tumor. Partial amputation of the penis is the only alternative in our practice context, an alternative often refuted.
\end{abstract}

\section{Keywords}

Glans Penis, Ulcerating Penis, Squamous Cell Carcinoma, Metastasis, Brachytherapy 


\section{Introduction}

Penile cancer is a rare malignant tumor that represents $0.5 \%$ of all male cancers in general [1] [2] [3]. It is the 4th most common urological cancer in men after prostate, bladder and kidney cancer. It is even rarer in populations that practice circumcision during childhood for ritual, religious or hygienic reasons. The diagnosis of certainty is anatomopathological. Squamous cell carcinoma is the histological type found in $95 \%$ of cases. In Europe, patients consulted early for minimal lesions benefit from conservative treatment, in particular Curie therapy and $\mathrm{CO}_{2}$ laser [3] [4]. On the other hand, in under-medicalized countries, patients consult late at the stage where the lesions are "florid, ulcerating or suppurating", requiring radical treatment that is often refuted by the patients [2] [5]. The authors report the clinical and anatomopathological aspects and the difficulties of management.

\section{Materiels and Methods}

This was a retrospective descriptive study of patients with a penile tumor during a 12-year period from January 2007 to December 2019 in the urology department of the University Hospital of National Reference (CHURN) in N'Djamena, Chad. Patients of sexual age with an ulcerated lesion of the penis, who came to the department for clinical and paraclinical evaluation and were diagnosed with penile cancer were included. The variables studied were of several kinds. The clinical variables included: the age of the patient, the appearance and location of the lesion, the age of the lesion and the general condition of the patient at the first consultation, the reason for the consultation, the notion of circumcision during childhood, the notion of previous treatment with "traditional practitioners and charlatans". Paraclinical variables: serologies (HIV, Chlamydia, syphilis), ECBU, the result of the analysis of the penile biopsy specimen, ultrasound of the urinary and abdominal tract, thoraco-abdominopelvic CT. Therapeutic variables: acceptance of partial amputation of the penis, adjuvant treatments (medical evacuation for chemotherapy or radiotherapy), duration of hospitalization, outpatient follow-up results.

Data were collected from the following registers: consultation, hospitalization, operative reports, and outpatient follow-up. The study was approved by the scientific ethics committee, the management of the RN University Hospital and the head of the urology department. The use of the photos was done in the respect of the patient's identity and consent. Data entry and analysis were done using Microsoft Office 2007 software, in particular Excel, Word and SPSS 18.0.

\section{Results}

In 10 years, we diagnosed and treated 8 cases of cancer of the penis. The average age of the patients was 60 years with extremes of 46 and 80 years. The reason for consultation was the presence of a suppurating ulcerated penile wound. The average age of the penile wound at the first medical consultation was 18.8 months 
with extremes of 4 months and 30 months. General condition was impaired on admission $(n=4)$. The patients were cattle breeders $(n=5)$, farmers $(n=2)$ and employees/civil servants $(n=1)$. Patients were circumcised $(n=6)$, uncircumcised $(n=2)$ and polygamous $(n=8)$. The lesion involved the body of the penis $(\mathrm{n}=6)$, the glans $(\mathrm{n}=2)$, the body of the penis and the glans $(\mathrm{n}=1)$ (Figures $1(A)-(D))$. The serologies were positive for: HIV $(n=1)$, chlamydia $(n=3)$ and syphilis $(\mathrm{n}=0)$. The histological analysis of the penile biopsy specimen concluded to a squamous cell carcinoma in all patients (Figure 2). Complementary examinations, in particular ultrasound and thoraco-abdominopelvic CT, revealed lesions that allowed the patients to be classified as $\mathrm{T} 2 \mathrm{~N}+\mathrm{M}+(\mathrm{n}=3)$ and T2N0M0 $(n=5)$. One patient had given consent for amputation of the penis (Figure 3).

\section{Discussion}

Penile cancer is rare cancer as evidenced by the scarcity of publications generally involving very few cases [6] [7] [8] [9]. In 12 years of study, we have diagnosed 8 documented cases of penile cancer in the Urology Department of the University Hospital of National Reference of N'Djamena in Chad. During this same period, we hospitalized 3255 patients, all urological pathologies included. Penile cancer is a cancer of men over 60 years of age in Europe where cancer registries are the best kept [10] [11]. In Senegal, penile cancer represents $0.97 \%$ of adult male cancers and $0.35 \%$ of all cancers [5]. In a large American series of 1605 cases

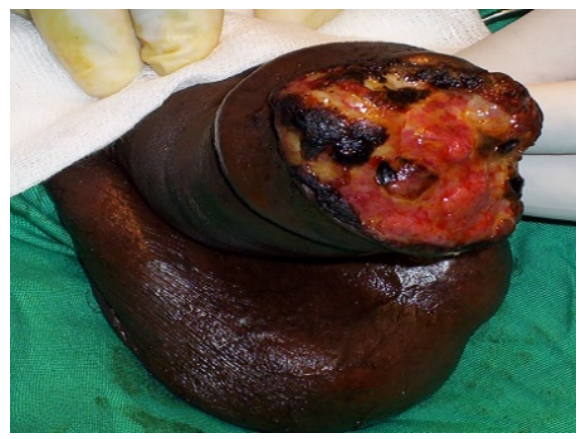

(A)

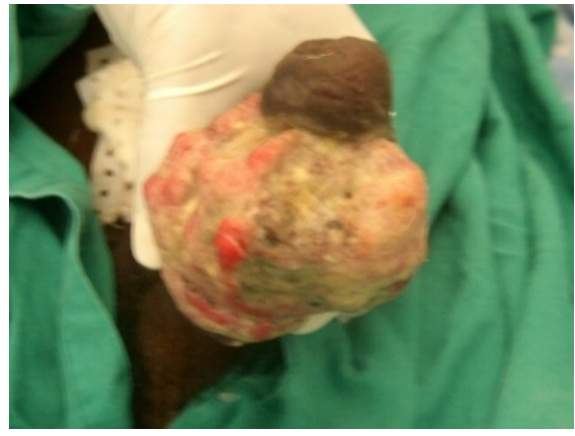

(C)

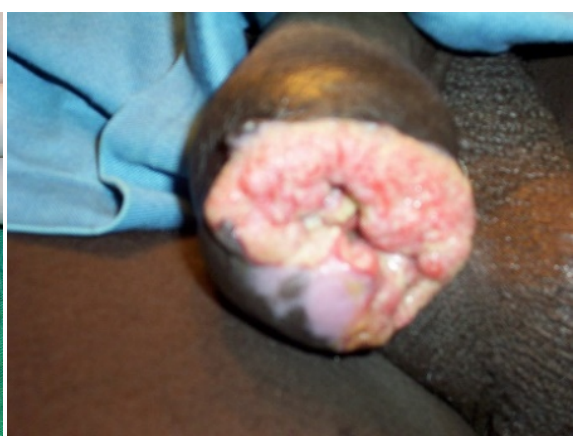

(B)

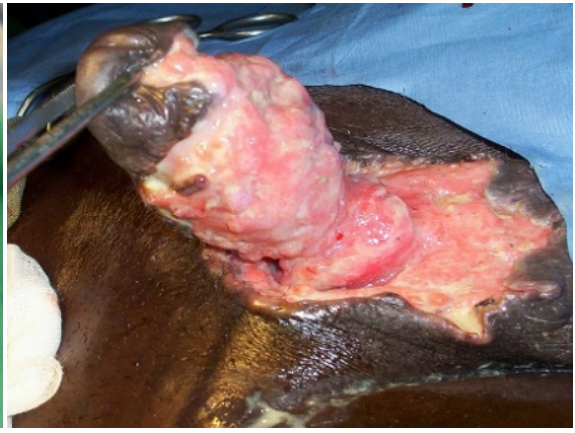

(D)

Figure 1. Different sites of penile cancer. (A) glandular; (B) preputial and glandular; (C) body of the penis; (D) glans and body of the penis. 


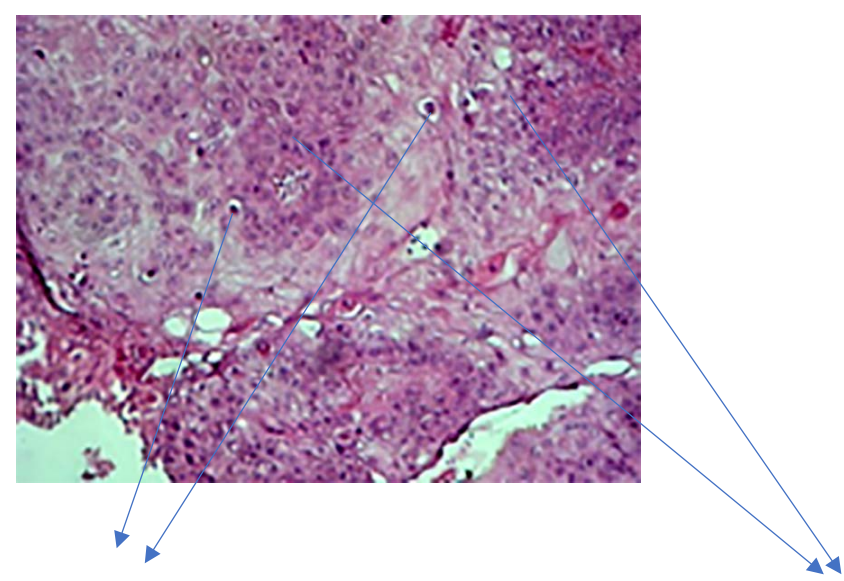

Koilocytes $=$ cells with a clear perinuclear hallo characteristic of an HPV lesion

Figure 2. Histological image of a verrucous squamous cell carcinoma of the penis. Proliferation of frankly malignant cells arranged in lobules and showing a clear squamous differentiation.

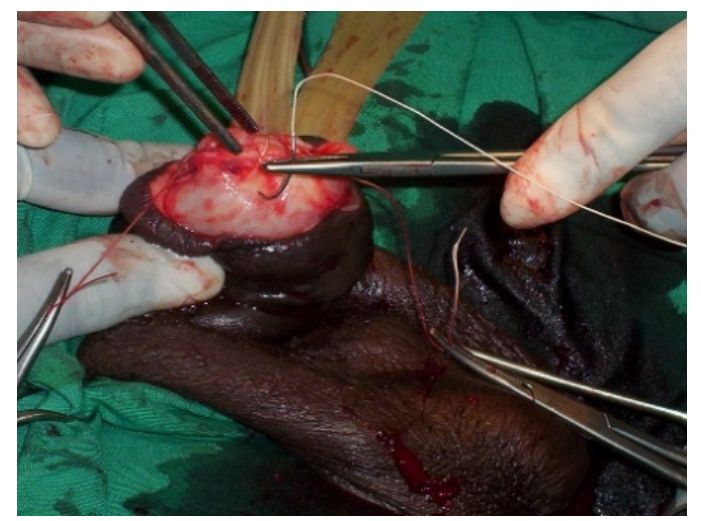

Figure 3. Surgical image of a partial penile amputation. Regularization of the proximal stump after amputation.

of penile cancer, 9.9\% of patients were African-American [2] [12]. The study found that all patients were polygamous. It should be noted that polygamy is well tolerated in Chad and should be considered as a favourable factor since it is synonymous with multiparity, which is a source of sexually transmitted infection. Although the average age at diagnosis is 60 years in our series, cancer of the penis seems to affect young people in Chad, as shown by the presence of two patients aged 54 and 46 years. The delay in the first consultation is notorious; the undeniable and visible witness of this delay is the monstrosity of the lesions observed. Indeed, there is a very long latency time between the patient's observation of the appearance of the first lesions of the penis and the first medical consultation. This precious time that could have been used in the hope of curing the disease is wasted in consulting "charlatans and other marabouts" in the first instance. These patients often go to the medical consultation under pressure from their parents who are bothered by the nauseating odor emanating from the tumor. This leads African authors to say that the diagnosis is often made at an ad- 
vanced stage of the disease, in connection with modesty, taboos and religious beliefs [5] [9]. This suggests that prevention necessarily involves education and communication to change behavior. The lesions observed are voluminous, budding, ulcerated, suppurated and in some cases infested with maggots. These lesions can be mistaken for Donovanosis, which is a bacterial infection caused by Klebsiella granulomatis, mainly genital and essentially sexually transmitted, predominant in tropical areas among livestock farmers. Giemsa and Whartin-Starry stains show Donovan bodies in the cytoplasm of macrophages, in the form of small rods swollen at each end. The lesions observed in our series are located on the glans penis where the distal part of the body of the penis and the glans penis in our series. According to the literature, malignant tumors of the penis are preferentially located on the glans [3]. Malignant tumors of the penis are often diagnosed in Europe at an early stage where the lesion is minimal and could be treated with brachytherapy or a minimalist surgical procedure with an acceptable carcinological safety margin. It is not easy to report with precision in our context that the tumor originated in the glans penis or in the body of the penis, as the tumor is so large and old at the first medical consultation that the patient may be confused. The glandular location of the lesion and the notion of the absence of circumcision often reported by the authors certainly suggest an insufficiency of local hygiene or a local infectious factor. Nowadays, circumcision is recognized as a protective factor against penile cancer provided that it is performed during childhood [8]. Circumcision is a common practice in Chad, either for religious reasons in the Muslim faiths or for hygienic, aesthetic, or even ritual reasons for Christians and animists. By removing the skin of the foreskin, circumcision leaves the glans exposed, facilitates its cleansing, and thus favors the keratinization of the glans, making it less vulnerable to papillomavirus and Acquired Immune Deficiency Syndrome (AIDS). The protective role of circumcision is evoked and retained in view of the low prevalence of penile cancer in populations that practice it and the increase in prevalence in those that do not practice it. However, a man with a flexible foreskin, allowing easy removal of the glans and correct genital hygiene, is as well preserved as a circumcised man [5]. This last hypothesis may explain the low number of cases in Europe, where circumcision is not systematic. The only histological type encountered in our series is squamous cell carcinoma, which according to the literature represents 95\% [9] [11]. Apart from one case of bulky inguinal adenopathy, one case of adenopathy detected by ultrasound and one case of hepatic metastasis, it is clear that the extension work-up was normal despite the monstrous nature of the lesions observed on the penis. This rarity of metastasis suggests that a local curative procedure can be performed, provided that the patients consult at an early stage and accept a partial penile amputation respecting the required carcinological margin. It should be emphasized that the development of cancer of the penis is slow. Invasion is local, distant metastases are rare. This slow development explains in part the delay in the first consultation. Despite the Florida appearance of the lesions observed in our patients, the extension workup at the time of diagnosis is 
Table 1. Distribution of patients according to refusal of penile amputation.

\begin{tabular}{|c|c|c|c|c|c|c|}
\hline Authors & Country & Year of publication & $\begin{array}{l}\text { Number } \\
\text { of patients }\end{array}$ & Average age & $\begin{array}{c}\text { Carcinoma } \\
\text { Squamous cell }\end{array}$ & $\begin{array}{c}\text { Refusal } \\
\text { of amputation }\end{array}$ \\
\hline Bah [13] & Guinea Conakry & 2007 & 2 & 39 & 2 & 0 \\
\hline Kara [3] & France & 2007 & 6 & 65.6 & 5 & 0 \\
\hline Odzébé [14] & Congo Brazza & 2010 & 1 & 42 & 1 & 1 \\
\hline Nouri [11] & Morocco & 2012 & 6 & 60.5 & 6 & 1 \\
\hline Sow [9] & Senegal & 2012 & 8 & 51.5 & 8 & 7 \\
\hline Kambou [2] & Burkina Faso & 2015 & 3 & 73.3 & 2 & 2 \\
\hline Mansouri [1] & Tunisia & 2018 & 11 & 64 & 9 & 4 \\
\hline Gueye [5] & Senegal & 1992 & 11 & 55 & 11 & 8 \\
\hline Our study & Chad & 2021 & 8 & 60 & 8 & 7 \\
\hline
\end{tabular}

poor. Three patients are classified as $\mathrm{T} 2 \mathrm{~N}+\mathrm{M}+$, the other 5 as T2N0M0. The treatment of penile cancer aims to reconcile two imperatives: destruction or removal of the tumor with a sufficient safety margin and cosmetic and functional preservation. The means used can be surgical (partial or total amputation of the penis or even emasculation) or physical (laser, radiotherapy or brachytherapy) [3] [4]. Surgical treatment, which is very mutilating, is poorly accepted by the population for psychological reasons [2] [5]. In the absence of radiotherapy in our practice context, partial amputation of the penis or, in the worst cases, emasculation remains the only alternatives in our practice context, refuted by 7 of the 8 patients. This refusal of amputation is also reported by other authors as shown in Table 1. It should be noted that in Africa in general and in Chad in particular, penile amputation is not accepted by patients for whom the penis is the visible expression of masculinity. Therefore, they would rather die than have their penis amputated, as Table 1 clearly shows.

There is only one palliative procedure left to perform, namely urinary diversion cystostomy for reasons of dysuria due to the invasion of the urethra and cleanliness in order to avoid soiling or even permanently irritating a lesion that is already over-infected and foul-smelling.

\section{Conclusion}

Penile cancer is rare cancer in men aged 50 years and older. Its diagnosis is late in our practice context where patients consult late at the stage of "florid" lesion from which emanates a nauseating odor. Squamous cell carcinoma is the only histological type encountered. The only possible surgical treatment is amputation of the penis, which is generally rejected by the patients.

\section{Conflicts of Interest}

The authors declare no conflicts of interest regarding the publication of this paper. 


\section{References}

[1] Mansouri, H., Ben Safta, I., Ayadi, M.A., Gadria, S., Ben Dhiab, T. and Rahal, K. (2018) Cancers primitifs de la verge: à propos de 11 cas et revue de la littérature. Pan African Medical Journal, 31, Article No. 14.

http://www.panafrican-med-journal.com/content/article/31/14/full/ https://doi.org/10.11604/pamj.2018.31.14.13077

[2] Kambou, T., Ouattara, A., Zaré, C., Zango, B., Kaboré, A., Konségré, V., et al. (2015) Le cancer de la verge à Bobo-Dioulasso (Burkina-Faso). A propos de 3 cas et revue de la littérature. Journal africain du cancerl African Journal of Cancer, 7, 64-68. https://doi.org/10.1007/s12558-014-0355-4

[3] Karra, H., Asselborn, E. and Fayollet, F. (2007) Cancer de la verge et laser dioxyde de carbone. À partir de six cas. Sexologies, 16, 85-90. https://doi.org/10.1016/j.sexol.2006.10.004

[4] Blanchard, P., Delannes, M. and Haie-Meder, C. (2013) Curiethérapie des cancers de la verge. Cancer/ Radiothérapie, 17, 140-142.

https://doi.org/10.1016/j.canrad.2012.12.002

[5] Gueye, S., Diagne, B.A., Ba, M., Sylla, C. and Mensah, A. (1992) Le cancer de la verge: aspects épidémiologiques et problèmes thérapeutiques au Sénégal. undefined. Médecined'Afrique Noire, 8, 582-584.

[6] Akers, C. and Holden, F. (2020) An Overview of the Diagnoses and Treatments for Penile Cancer. British Journal of Nursing (Mark Allen Publishing), 29, S6-14.

https://doi.org/10.12968/bjon.2020.29.9.S6

[7] Pekala, K.R., Pelzman, D., Theisen, K.M., Rogers, D., Maganty, A., Fuller, T.W., et al. (2019) The Prevalence of Penile Cancer in Patients With Adult Acquired Buried Penis. Reconstructive Urology, 133, 229-233.

https://doi.org/10.1016/j.urology.2019.07.019

[8] Colberg, C., van der Horst, C., Jünemann, K.-P. and Naumann, C.M. (2018) Epidemiology of Penile Cancer. Der Urologe, 57, 408-412.

https://doi.org/10.1007/s00120-018-0593-7

[9] Sow, Y., Thiam, A., Fall, B., Coulibali, M., Sarr, A., Diao, B., et al. (2012) Cancer du pénis au Sénégal: aspects cliniques et thérapeutiques. Basic and Clinical Andrology, 22, 102-107. https://doi.org/10.1007/s12610-012-0176-1

[10] Grobet-Jeandin, E. (2020) Recommandations sur la prise en charge du cancer du pénis. Urologie in der Praxis, 22, 105-110.

https://doi.org/10.1007/s41973-020-00110-1

[11] Nouri, A., Elkarni, H., Yacoubi, S.E., Karmouni, T., Kahder, K.E., Koutani, A., et al. (2012) Cancer du pénis: A propos de 6 cas avec Revue de la littérature. African Journal of Urology, 18, 66-70. https://doi.org/10.1016/j.afju.2012.04.014

[12] Pascual, A., Pariente, M., Godínez, J.M., Sánchez-Prieto, R., Atienzar, M., Segura, M., et al. (2007) High Prevalence of Human Papillomavirus 16 in Penile Carcinoma. Histology and Histopathology. 22, 177-182.

[13] Bah, O.R., Guirassy, S., Diallo, A.B., Keita, Y., Balde, S., Bah, I., et al. (2007) Le carcinome epidermoïde de la verge: A propos de deux observations au CHU de Conakry. African Journal of Urology, 13, 291-295.

[14] Odzébé, A.W.S., Bouya, P.A., Nkoua Mbon, J.B., Ngatshé, A. and Péko, J.F. (2010) Le cancer de la verge: à propos d'un cas et revue de la littérature. Basic and Clinical Andrology, 20, 273-275. https://doi.org/10.1007/s12610-010-0100-5 